\title{
Isothermal Imidization of an Aromatic Polyimide Precursor Studied by Fluorescence Spectroscopy
}

\author{
Masatoshi Hasegawa, Hisae AraI,* Itaru Mita, \\ and Rikio YoKota** \\ Research Center for Advanced Science and Technology, \\ The University of Tokyo, 4-6-1, Komaba, \\ Meguro-ku, Tokyo 153, Japan \\ * Toho University \\ ** Institute of Space and Astronautical Science
}

(Received May 1, 1990)

\begin{abstract}
Isothermal imidization of an aromatic polyimide (PI) precursor, poly(amic acid) (PAA) derived from biphenyltetracarboxylic dianhydride (BPDA) and $p$-phenylene diamine (PDA) was studied in solution and the solid state using intermolecular charge-transfer (CT) fluorescence reflecting sensitively the degree of molecular aggregation of polyimides. Isothermal imidization was carried out in a hand-made furnace which makes possible to jump the temperatures of samples to the established reaction temperatures by inserting the samples into a slit in the temperature-controlled heating block. The degree of imidization (i) was determined by IR spectroscopy. When imidized at $110^{\circ} \mathrm{C}$ in solution $(10 \mathrm{wt} \%)$, the fluorescence of the as-cast films reduced rapidly and became very weak at about $30 \%$ in conversion. In the solid state, as imidization proceeded, the fluorescence of the PAA reduced rapidly as well as in solution, and then the CT fluorescence of the PI increased. The relationship between the intensity and the conversion clearly shows that the fluorescence intensity at a same conversion depends strongly on the imidization temperature $\left(T_{\mathrm{i}}\right)$. For example, when imidized at $150^{\circ} \mathrm{C}$ the intensity increases only slightly as the reaction proceeds, while at higher $T_{\mathrm{i}}$ such as 230 or $270^{\circ} \mathrm{C}$ the intensity increases rapidly. This indicates that the degree of the molecular order in the PI formed on isothermal imidization depends strongly on $T_{\mathrm{i}}$.

KEY WORDS Polyimide / Isothermal Imidization / CT Fluorescence /
\end{abstract}

Excellent mechanical and electrical properties, as well as thermal stability, of aromatic PIs have been applied in many kinds of fields. Mechanical properties such as Young's modulus and elongation strength of the rigid rod PI films ${ }^{1}$ and PI/PI molecular composites $(\mathrm{MC})^{2}$ can be remarkably improved by imidization after cold drawing of PAAs and additional heat treatment. For PI/PI MC, it is also important to control miscibility. It has been widely recognized that some physical properties are largely affected by not only chemical structures but also the orientation of polymer chains and aggregated structure. Kochi et al. reported that dynamic mechanical properties of some PIs depend strongly on the degree of the molecular aggregation. ${ }^{3}$ A number of workers studied the morphology of a PI using WAXD $,{ }^{4-7} \mathrm{SAXS},{ }^{8-10} \mathrm{UV}$ and laser Raman spectroscopy ${ }^{11,12}$ and fluorescence method, ${ }^{13,14}$ and showed the existence of the molecular order which grew up by annealing and especially by increasing $T_{\mathrm{i}}$. It is very important to examine the relation between the morphologies of the final PIs and the imidization reaction mechanisms. The kinetics and mechanisms of thermal imidization of large kinds of PAAs were systematically examined by Bessonov and coworkers ${ }^{15}$ and other groups ${ }^{16,17}$ using IR spectroscopy and thermo- 
gravimetry. UV-vis absorption spectroscopy has scarcely been used for studies on imidization. ${ }^{18}$ Recently Pyun et al. analyzed quantitatively the changes of chemical structure from PAA to PI during thermal imidization in solution and in the solid state using UV-vis absorption spectrum of an azocompound (diamine component). ${ }^{19}$ But to our knowledge, no work has been done on the relation between the imidization mechanisms and the molecular aggregation of final PIs. In this paper, we show how the molecular order is formed with the progress of the reaction using the intrinsic intermolecular CT fluorescence of a PI which reflects sensitively the aggregated structures $^{14}$ and the miscibility of PI/PI blends. $^{20}$

\section{EXPERIMENTAL}

Biphenyltetracarboxylic dianhydride (BPDA) was recrystallized from dried acetic anhydride and then vacuum dried at more than $180^{\circ} \mathrm{C}$ for $24 \mathrm{~h}$. DMAc used for the preparation of PAA was dried with molecular sieves (4A) and then vacuum distilled. Zone refining $p$-phenylene diamine (PDA) supplied by Honda Giken Co., Ltd. was used after vacuum drying at room temperature without further purification. The PAA derived from BPDA and PDA (PAA(BPDA/PDA)) was prepared by adding a stoichiometric amount of BPDA powder to the DMAc solution of PDA with continuous stirring in a nitrogen atmosphere. A viscous yellow PAA solution $(10 \mathrm{wt} \%)$ was obtained after several hours. PAA films were prepared by casting onto a glass plate at $50^{\circ} \mathrm{C}$ for $2 \mathrm{~h}$ in air oven, followed by vacuum drying at $50^{\circ} \mathrm{C}$ for $24 \mathrm{~h}$.

Two kinds of heating furnaces were used for the thermal imidization of PAA films, a common furnace with slow heating rate (the time required up to $T_{\mathrm{i}}$ is $15-20 \mathrm{~min}$ ), and a special furnace with a rapid heating rate (about $5 \mathrm{~s}$ ). The rapid-heating furnace, which is mainly used for isothermal imidization, is equipped with a heating block surrounded with a heat insulator, nitrogen conduction tube and thermocontroller. Rapid heating of the samples becomes possible by quickly inserting the samples wrapped in aluminum foil into slit in the temperature-controlled heating block and by maintaining the intimate contact between the samples and inside wall in the slit. Sample temperature was detected by a thin thermocouple in contact with the samples.

Thick films $(30-50 \mu \mathrm{m})$ and thin films $(2-5 \mu \mathrm{m})$ were used for fluorescence and IR measurements, respectively. Although there is a report that the imidization rate is affected by the amounts of residual solvent which depends on the film thickness, ${ }^{21}$ since the polymer chains in the region from the surface to the depth at a few $\mu \mathrm{m}$ are mainly excited by incident light of $350 \mathrm{~nm}$ for fluorescence measurement because the optical density at $350 \mathrm{~nm}$ of $3 \mu \mathrm{m}$ thick film of both the PAA and the PI is more than 2, it is reasonable to substitute the degree of the imidization of the thick films used for the fluorescence measurement for that of the thin films used for IR measurement. In order to prevent foaming of the PAA films due to residual solvent when imidized at more than $230^{\circ} \mathrm{C}$, preheating at $150^{\circ} \mathrm{C} ; 1 \mathrm{~min}$ prior to the isothermal reaction, which is harmless except for only slight imidization (less than $8 \%$ ), was carried out.

The fluorescence spectra of PI were measured at room temperature using a fluorescence spectrophotometer (Hitachi, model 850). The PI films were excited at $350 \mathrm{~nm}$ in a front-face arrangement using $5 \mathrm{~nm}$ bandpasses for both the excitation and emission monochromators, respectively. The degree of imidization (i) was estimated by the absorbance ratio of $1774 \mathrm{~cm}^{-1}$ band $(\mathrm{C}=\mathrm{O}$ stretching in imide rings) to that for the PI annealed at $300^{\circ} \mathrm{C}$ for $20 \mathrm{~min}$ $(i=100 \%)$ using $1517 \mathrm{~cm}^{-1}$ band $(\mathrm{C}=\mathrm{C}$ stretching in benzene ring in PDA) as a internal standard, using IR spectrophotometer (Jasco, model IR-700). The densities of PI films produced under some thermal conditions were 
measured using a density gradient column (xylene- $\mathrm{CCl}_{4}$ system). The extinction coefficients at $350 \mathrm{~nm}$ of PI and PAA films were determined from the film thickness and absorbance using a UV-vis spectrophotometer (JASCO, model UVIDEC-660).

$\eta_{\mathrm{SP}} / c$ and $\varepsilon$ at $350 \mathrm{~nm}$ of PAA and PI used is shown in Table I.

\section{RESULTS AND DISCUSSION}

The thermal imidization of PAA occurs through nucleophilic attack on the carbonyl carbon in carboxyl group by the lone pair of amide nitrogen. Two kinds of side reactions, the formation of polyisoimide and reversible chain scission as shown in Scheme 1 are known. polyisoimide is hardly formed by thermal imidization but is observed by IR spectroscopy (isoimide: $1800 \mathrm{~cm}^{-1}$ ) in chemical imidization. ${ }^{22}$ Polyisoimide can be thermally rearranged to PI. ${ }^{23}$ The chain scission of PAA into amines and anhydrides during thermal imidization is observed with IR spectroscopy (anhydride: $1850 \mathrm{~cm}^{-1}$ ). But the amounts of anhydride decrease (resynthesis) as imidization proceeds $^{24}$ and the anhydrides disappear completely when cured at above $300^{\circ} \mathrm{C}$.

Since PI(BPDA/PDA) has very rigid main

Table I. $\eta_{\mathrm{sp}} / c$ and $\varepsilon$ of PAA and PI used

\begin{tabular}{ccc}
\hline Symbol & $\eta_{\mathrm{sp}} / c / \mathrm{dlg}^{-1 \mathrm{a}}$ & $\varepsilon_{350} / \mathrm{M}^{-1} \mathrm{~cm}^{-1}$ \\
\hline PAA(BPDA/PDA) & 1.5 & 1400 \\
PI(BPDA/PDA) & - & 2300 \\
\hline
\end{tabular}

a Measured at $0.5 \mathrm{wt} \%$ polymer concentration.

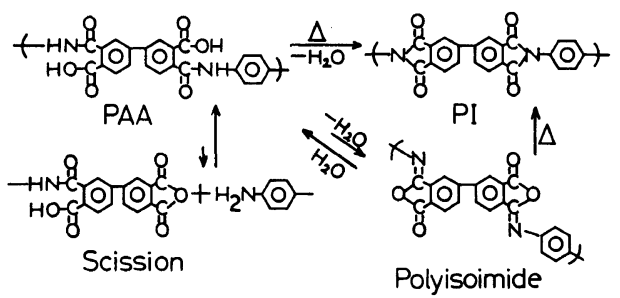

Scheme 1. Reaction scheme of thermal imidization. chains and high $T_{\mathrm{g}}$ (it does not show a clear $T_{\mathrm{g}}$ ), with the progress of imidization, molecular mobility decreases quickly. It is expected that PI formed on thermal imidization are in a non-equilibrium state and depend strongly on imidization conditions such as $T_{\mathrm{i}}$ and heating rates up to $T_{\mathrm{i}}$. This will be illustrated by the following preliminary experiment. PI films having different molecular packings were prepared under some cure conditions in Table $I$ in a furnace at a slow heating rate (time required up to $T_{\mathrm{i}}: 15-20 \mathrm{~min}$ ) in vacuum. It was observed by IR measurement that the imidization is almost completed by curing at $200^{\circ} \mathrm{C} ; 5 \mathrm{~h}$, naturally at $300^{\circ} \mathrm{C} ; 1 \mathrm{~h}$ and at $400^{\circ} \mathrm{C} ; 1 \mathrm{~h}$ too. Also annealing time at various conditions is long enough to complete the cure. Figure 1 shows that the intermolecular CT fluorescence intensity for the PIs prepared on same conditions in Table II is linearly related with the density. This indicates that it is possible to evaluate the molecular packing of the PI using CT fluorescence. The relation of the intensity to flnal cure temperature is shown in Figure 2. With increasing $T_{\mathrm{i}}$, fluorescence intensity increases (sample No. 1, 5, 7).

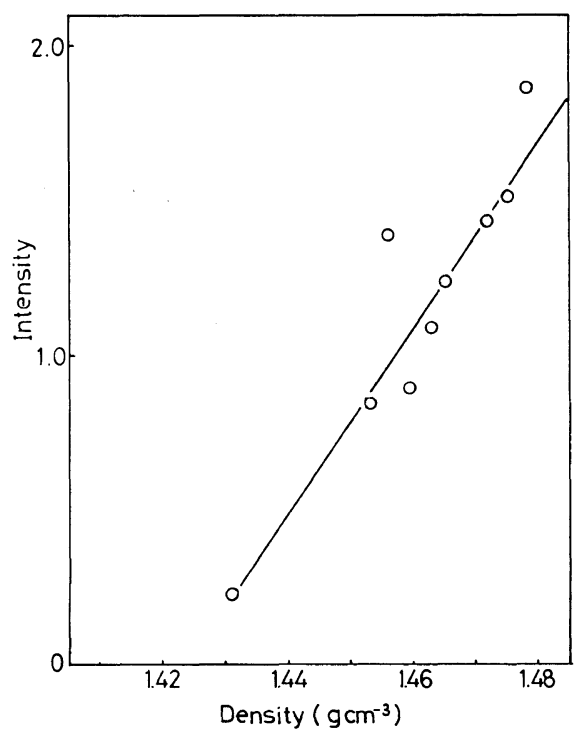

Figure 1. Relationship between fluorescence intensity and desity of PIs cured on the conditions in Table II. 
Table II. Cure history of samples

\begin{tabular}{cccc}
\hline \multirow{4}{c}{ Cure history } \\
\cline { 2 - 4 } Sample No. & $200^{\circ} \mathrm{C} ; 5 \mathrm{~h}$ & $300^{\circ} \mathrm{C} ; 1 \mathrm{~h}$ & $400^{\circ} \mathrm{C} ; 1 \mathrm{~h}$ \\
\hline 1 & $\bigcirc$ & & \\
2 & $\bigcirc$ & $\bigcirc$ & \\
3 & $\bigcirc$ & & $\bigcirc$ \\
4 & $\bigcirc$ & $\bigcirc$ & $\bigcirc$ \\
5 & & 0 & \\
6 & & 0 & $\bigcirc$ \\
7 & & & $\bigcirc$ \\
\hline
\end{tabular}

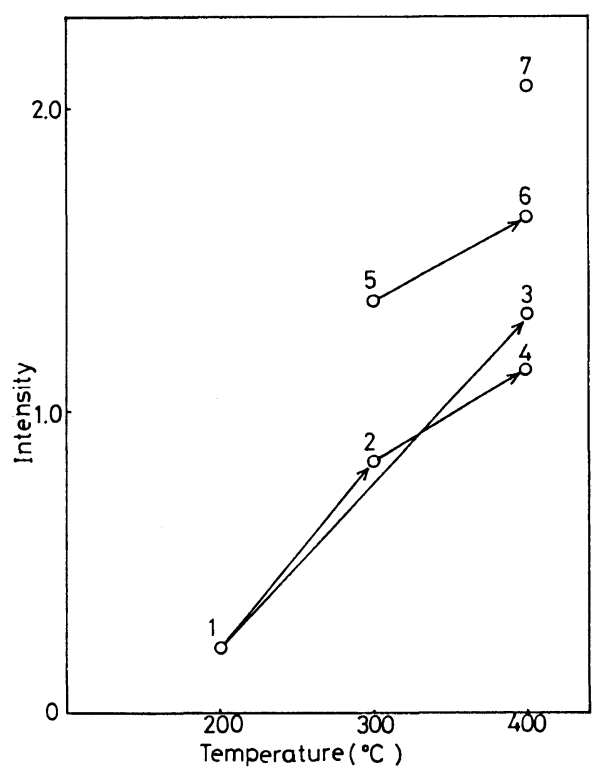

Figure 2. Change of fluorescence intensity against final cure temperature.

Comparing PI cured at $400^{\circ} \mathrm{C} ; 1 \mathrm{~h}$ (No. 7) with PI cured at $200^{\circ} \mathrm{C} ; 5 \mathrm{~h}+400^{\circ} \mathrm{C} ; 1 \mathrm{~h}$ (No. 3), in spite of the same final cure temperature $\left(400^{\circ} \mathrm{C}\right)$, the fluorescence intensity of sample No. 3 is far smaller than that of No. 7. A similar result is shown in the case of $300^{\circ} \mathrm{C}$. In sample No. 3 , since the imidization at $200^{\circ} \mathrm{C} ; 5 \mathrm{~h}$ before flnal annealing at $400^{\circ} \mathrm{C}$ makes a PI with loose packing $^{25}$ but with rigid polymer chains, the effect of the final annealing is reduced due to the rigid chains. The molecular packing of sample No. 3 remains loose. In other words,

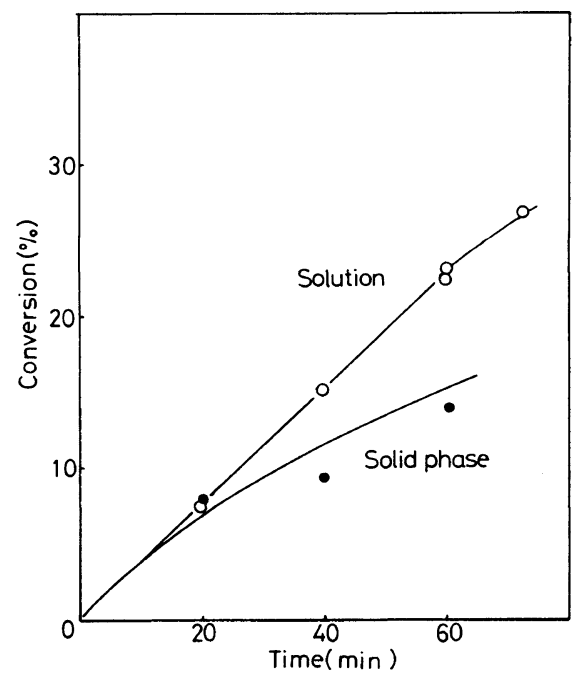

Figure 3. Time-conversion curves for isothermal imidization at $110^{\circ} \mathrm{C}$ in solution and in the solid phase.

sample No. 3 is in a non-equilibrium state. On the other hand, the cure at $400^{\circ} \mathrm{C}$ of the PAA with flexible chains $\left(T_{\mathrm{g}}=\mathrm{ca} .140^{\circ} \mathrm{C}\right)$ (No. 7) yields a very dense PI. This means that the degree of the molecular packing of rigid PI is not always determined by only the final cure temperatures. In fact, since the rigidity of the polymer chains increases rapidly with the progress of imidization, the relation between reaction kinetics and formation of aggregated structures is very complex. Also since the heating rates of the furnace used are slow (it takes $15-20 \mathrm{~min}$ ), in the cure at $400^{\circ} \mathrm{C} ; 1 \mathrm{~h}$, samples are not only subjected to the imidization reaction which completes at around $200^{\circ} \mathrm{C}$ on the way to the temperature rising, but also the annealing of the PI imidized at around $200^{\circ} \mathrm{C}$. In order to consider both effects separately, imidization was carried out under conditions without annealing effect in the rapid-heating furnace.

\section{Kinetics of Isothermal Imidization and Changes of CT Fluorescence}

Time-conversion curves of thermal imidization at $110^{\circ} \mathrm{C}$ in DMAc solution $(10 \mathrm{wt} \%)$ and in solid state are shown in Figure 3. The 

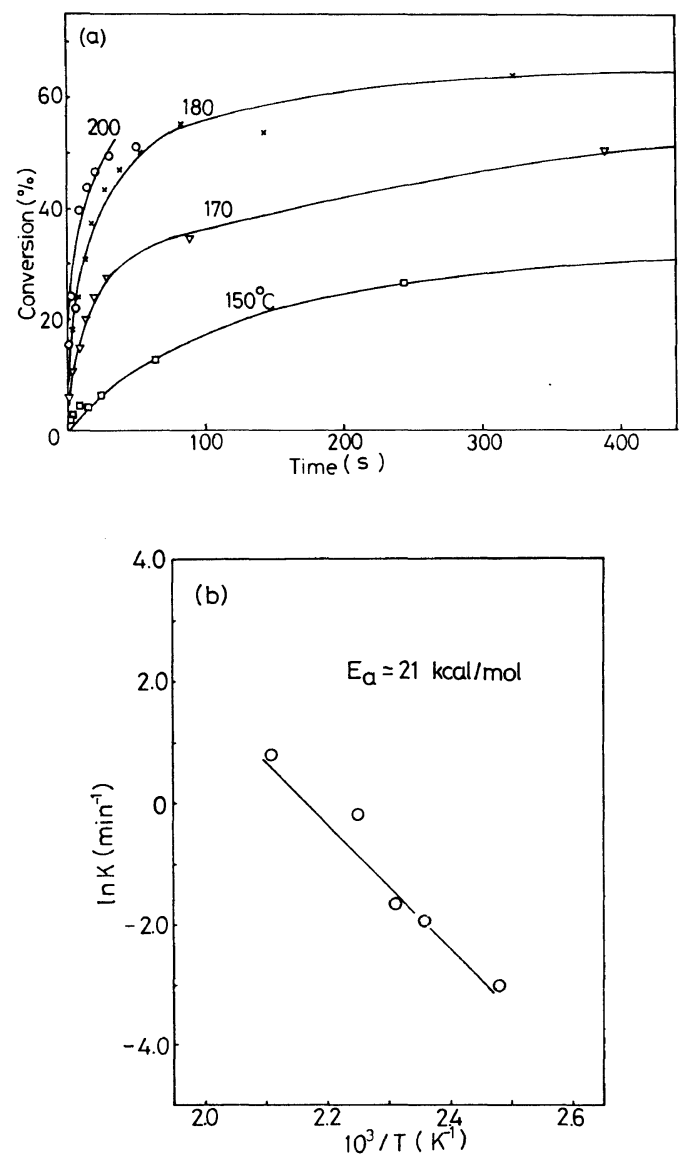

Figure 4. Time-conversion curves for isothermal imidization at $150-200^{\circ} \mathrm{C}$ in the solid phase (a) and an Arrhenius plot (b).

imidization in solution proceeds rapidly compared with that in the solid phase although above $30 \%$ conversion an insoluble portion is obtained. But the reaction in the solid phase is very slow at $110^{\circ} \mathrm{C}$. Possibly, the conformation changes required with the reaction are free in solution but in the glassy state, this is suppressed. It is known that the reaction rates in solid PAAs suddenly increases above $c a$. $150^{\circ} \mathrm{C}$. Figure 4 shows time-conversion curves for isothermal imidization at $150-200^{\circ} \mathrm{C}$ in solid PAA. The reaction rates increase with increasing $T_{\mathrm{i}}$. The apparent activation energy $E_{\mathrm{a}}$ determined from an Arrhenius plot of the initial rate constants was about $21 \mathrm{kcal} \mathrm{mol}^{-1}$.

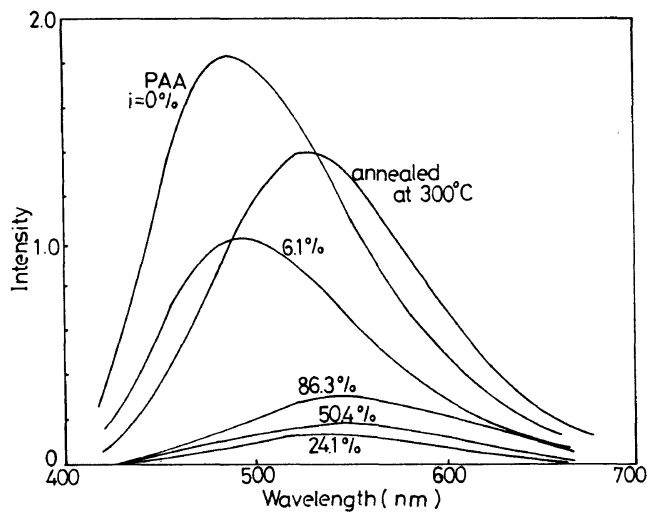

Figure 5. Change of fluorescence spectra with the progress of imidization at $170^{\circ} \mathrm{C}$.

This value is consistent with the data of Bessonov et al. in which the activation energy is nearly constant regardless of the chemical structures of PAAs, being about $19 \mathrm{kcal}$ $\mathrm{mol}^{-1} .^{15}$

Isothermal imidization of solid PAA was also examined using intermolecular CT fluorescence of PI. Figure 5 shows the changes of the fluorescence spectra and degree of imidization. The fluorescence of the PAA peaking near $490 \mathrm{~nm}$ reduces rapidly with imidization, and then becomes very weak at $20-30 \%$ in conversion. When the reaction proceeds further, the fluorescence of PI peaking at $530-540 \mathrm{~nm}$ increases gradually. Similarly, the rapid reduction of PAA fluorescence was also observed for imidization at $110^{\circ} \mathrm{C}$ in solution and in the solid phase. However, the rapid reduction of the PAA fluorescence in the region of very low conversion can not be easily explained. The following possibilities are proposed. First, even if the concentrations of imide moieties are low at low conversion, the extinction coefficient of imide unit formed by imidization is quite large compared to the amic acid unit and thus the incident light is selectively absorbed by imide units distributed randomly. Second, after effective energy transfer from PAA units to PI units occurs, unless intermolecular CT sites exist at low conversion, the CT fluorescence is not 


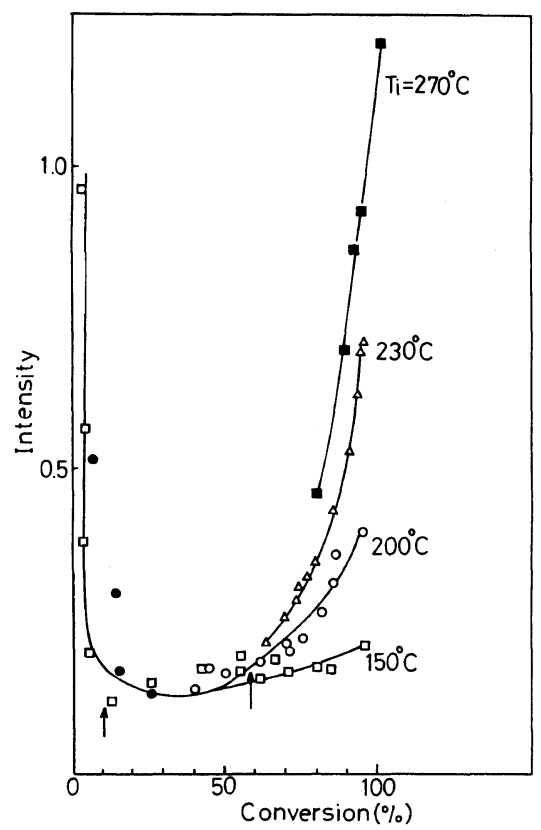

Figure 6. Fluorescence intensity as a function of conversion.

observed. As shown in Table I, since the extinction coefficients of the PAA and the corresponding PI are 1400 and $2300\left(\mathrm{M}^{-1} \mathrm{~cm}^{-1}\right)$ respectively, the first is excluded. Although it is not yet clear whether the rapid reduction of PAA fluorescence at the initial stage of the reaction is attributed to the energy transfer, since our main concern is to know the relation between the aggregated structures of final PI and thermal imidization reaction, we wish to focus on changes of the CT fluorescence of the PI in the region from the middle to the final reaction stage.

Figure 6 shows the changes of the fluorescence intensity with the progress of imidization at various $T_{\mathrm{i}}$. The reaction rates are so large at higher $T_{\mathrm{i}}$ that it was experimentally difficult to follow the reactions in the low conversion range. As shown in Figure 6 , the intensity begin to increase gradually from around $50 \%$ in conversion, showing that the formation of CT structure occurs simultaneously with the progress of the reaction. It is

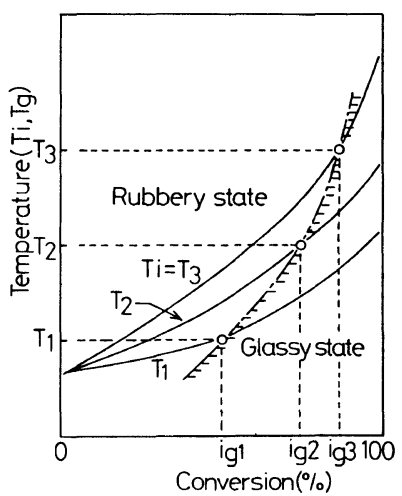

Figure 7. Schematic diagram for changes of $T_{\mathrm{g}}$ with the progress of imidization.

evidently shown that when imidized at $150^{\circ} \mathrm{C}$ the intensity increases only slightly with the progress of the reaction while at higher $T_{\mathrm{i}}$ such as $270^{\circ} \mathrm{C}$ the increase of intensity become remarkable. That the molecular packing of the final PI is strongly affected by the reaction temperature suggests that the molecular mobility of the polymer chains on the way to imidization is closely related to the molecular packing. Also, it is noted that from about $60 \%$ conversion the intensity-conversion curves begin to branch and the intensity at a same conversion depends strongly on $T_{\mathrm{i}}$. If the CT fluorescence does not provide information for intermolecular aggregation but intramolecular information, only one intensity-conversion curve must be depicted regardless of $T_{\mathrm{i}}$ (do not branch). Figure 7 shows a schematic diagram based on intensity-conversion curves for changes of $T_{\mathrm{g}}$ of the polymer with the progress of the reaction at some $T_{\mathrm{i}}$ More than 20 years ago we proposed ${ }^{26,27}$ the concept, which has been widely accepted, of stopping of polymerization of vinyl monomers and crosslinking system at the conversion of vitrification. This concept can be also used to the thermal imidization reaction in solid phase. As the reaction proceeds, the $T_{\mathrm{g}}$ of the polymer increases successively, and exceeds the $T_{\mathrm{i}}$ at certain conversion $\left(i_{\mathrm{g}}\right)$ where the polymer is in the glassy state. The more $T_{\mathrm{i}}$ increases, the more $i_{\mathbf{g}}$ will increase, too. In Figure 7 , it is 


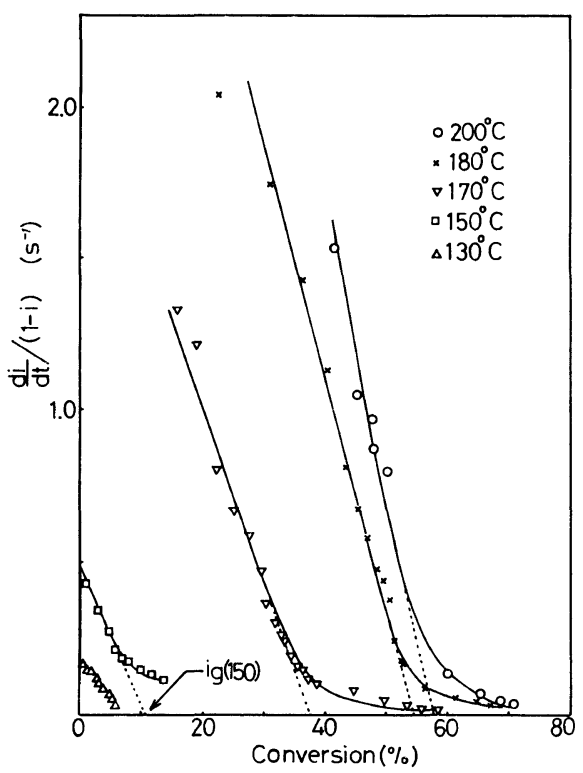

Figure 8. Apparent rate constant versus the conversion.

difficult to determine experimentally the $T_{\mathrm{g}}$ of the partial imidized PAAs by thermal analysis such as TMA or DSC or dynamic mechanical analysis because imidization occurs due to heating. Laius et al. showed that the value of $i_{\mathrm{g}}$ determined from the plot of conversionrate constant as shown in Figure 8 agrees with the data obtained by the stepwise pulse heating method. ${ }^{28}$ The arrows marked in Figure 6 denote $i_{\mathrm{g}}$ determined from Figure 8 at 150 and $200^{\circ} \mathrm{C}$ respectively. In the case of $150^{\circ} \mathrm{C}$ vitrification occurs at only initial stage, but for the reaction at $200^{\circ} \mathrm{C}$, it takes place at around $60 \%$ conversion. It seems that packing at final PI is already determined before vitrification $\left(i_{\mathrm{g}}\right)$ because above $i_{\mathrm{g}}$ the molecular motion enough to rearrange the polymer chains is inadequate. In other words, the degree of increase of the intensity (packing) after the vitrification depends strongly on the amounts of $i_{\mathrm{g}}$. Accordingly, to gain more packed PI, it is necessary to have higher $i_{\mathrm{g}}$, to increase $T_{\mathrm{i}}$.

\section{CONCLUSIONS}

Isothermal imidization of a solid PAA was examined using the intermolecular CT fluorescence reflecting sensitively the molecular packing of PI chains. The relationship between the fluorescence intensity and the conversion clearly shows that the intensity at a same conversion depends strongly on the $T_{\mathrm{i}}$ and the intensity increases remarkably at higher $T_{\mathrm{i}}$ such as $270^{\circ} \mathrm{C}$. The increase of $\mathrm{CT}$ sites occurs simultaneously with the progress of the reaction. The gradient in the intensity-conversion curve after the vitrification increases with $i_{\mathrm{g}}$.

\section{REFERENCES}

1. M. Kochi, T. Uruji, T. Iizuka, I. Mita, and R. Yokota, J. Polym. Sci., C, 25, 441 (1987).

2. R. Yokota, R. Horiuchi, M. Kochi, H. Soma, and I. Mita, J. Polym. Sci., C, 26, 215 (1988).

3. M. Kochi and H. Kambe, Polym. Eng. Rev., 3, 355 (1983).

4. N. Takahashi, D. Y. Yoon, and W. Parrish, Macromolecules, 17, 2583 (1984).

5. T. P. Russell, H. Gugger, and J. D. Swalen, J. Polym. Sci., Polym. Phys. Ed., 21, 1745 (1983).

6. L. G. Kazaryan, D. Ya. Tsvankin, B. M. Ginzburg, Sh. Tuichiev, L. N. Korzhavin, and S. Ya. Frenkel, Polym. Sci. U.S.S.R., 14, 1344 (1972).

7. G. Conte, L. D'Illario, N. N. Pavel, and E. J. Giglio, J. Polym. Sci., Phys. Ed., 14, 1553 81976).

8. S. Isoda, H. Shimada, M. Kochi, and H. Kamber, J. Polym. Sci., Polym. Phys. Ed., in press.

9. T. P. Russell, J. Polym. Sci. Polym. Phys. Ed., 22, 1105 (1984).

10. T. P. Russell and H. R. Brown, J. Polym. Sci., B, 25, 1129 (1987).

11. H. Ishida, S. T. Wellinghoff, E. Baer, and J. L. Koenig, Macromolecules, 13, 826 (1980).

12. S. T. Wellinghoff, H. Ishida, J. L. Koenig, and E. Baer, Macromolecules, 13, 834 (1980).

13. E. D. Wachsman and C. W. Frank, Polymer, 29, 1191 (1988).

14. M. Hasegawa, M. Kochi, I. Mita, and R. Yokota, Eur. Polym. J., 25, 349 (1989).

15. M. I. Bessonov, M. M. Koton, V. V. Kudryavtsev, and L. A. Laius, Ed., "Polyimides," Plenum Press, New York, N.Y., 1987.

16. S. Numata, K. Fujisaki, and N. Kinjo, in "Polyimides," Vol. 1, K. L. Mittal, Ed., Plenum Press, New York, N.Y., 1984, p 259. 
17. I. Mita, M. Akiba, A. Sato, and M. Kochi, Proceedings of European Technical Conference on Polyimides, Vol. 1, Monpellier, 1989, A7.

18. N. N. Barashkov, L. I. Semenova, and R. N. Nurmukhametov, Polym. Sci. U.S.S.R., 25, 1264 (1983).

19. E. Pyun, R. J. Mathisen, and C. S. P. Sung, Macromolecules, 22, 1174 (1989).

20. M. Hasegawa, M. Kochi, I. Mita, and R. Yokota, Polymer, submitted.

21. R. Ginsburg and J. R. Susko, in "Polyimides," Vol. 1, K. L. Mittal, Ed., Plenum Press, New York, N.Y., 1984, p 237.

22. R. A. Dine-Hart and W. W. Wright, J. Appl. Polym. Sci., 11, 609 (1967).
23. V. V. Kudryavtsev, M. M. Koton, T. K. Meleshko, and V. P. Sklizkova, Polym. Sci. U.S.S.R., 17, 2029 (1975).

24. M. I. Tsapovetskii, L. A. Laius, T. I. Zhukova, L. A. Shibayev, N. G. Stepanov, M. I. Bessonov, and M. M. Koton, Polym. Sci.U.S.S.R., 30, 295 (1988).

25. R. Yokota, Doctoral thesis, University of Tokyo (1990).

26. K. Horie and I. Mita, J. Polym, Sci., Polym. Chem. $E d$., 6, 2663 (1968).

27. I. Mita and K. Horie, J. Macromol. Sci. Rev., Macromol. Chem., 91 (1987).

28. L. A. Laius, M. I. Bessonov, and E. S. Florinskii, Polym, Sci. U.S.S.R., 13, 2257 (1971). 